\title{
What is the rhythm?
}

\section{A. W. G. J. Oomen ${ }^{1} \cdot$ R. W. Sy $y^{1,2}$}

Published online: 31 August 2018

(C) The Author(s) 2018

A 22-year-old female presented with a history of palpitations. During follow-up the electrocardiogram (ECG) shown below (Fig. 1) was recorded. Her baseline ECG during sinus rhythm showed no pre-excitation. Physical examination and echocardiogram were both unremarkable.

What is the most likely diagnosis for the arrhythmia?

\section{Answer}

You will find the answer elsewhere in this issue.

Open Access This article is distributed under the terms of the Creative Commons Attribution 4.0 International License (http:// creativecommons.org/licenses/by/4.0/), which permits unrestricted use, distribution, and reproduction in any medium, provided you give appropriate credit to the original author(s) and the source, provide a link to the Creative Commons license, and indicate if changes were made.

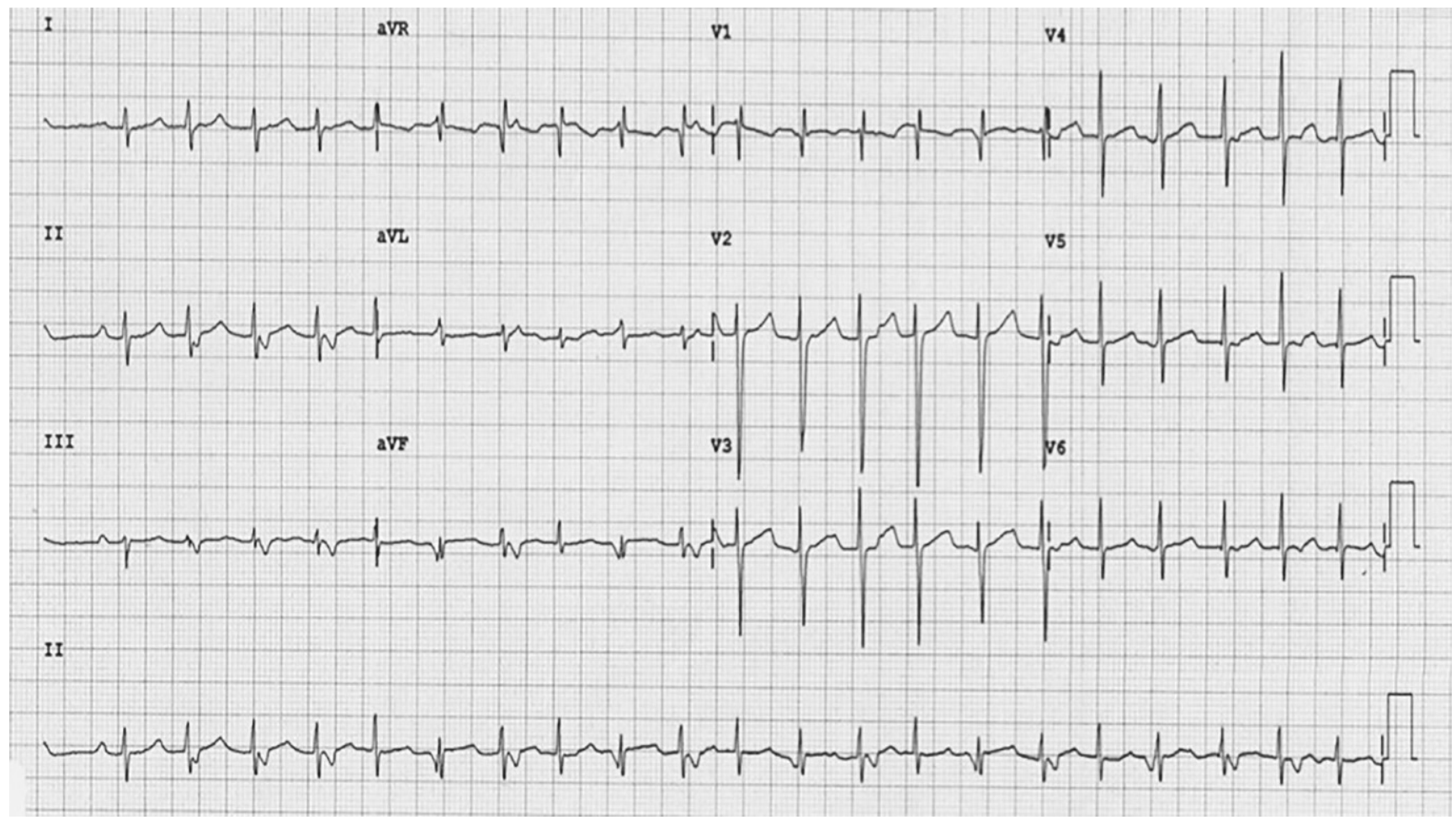

Fig. 1 ECG at presentation

R. W. Sy

raymond.sy01@gmail.com

1 Department of Cardiology, Royal Prince Alfred Hospital,

Camperdown, NSW, Australia

2 Sydney Medical School, University of Sydney,

Sydney, NSW, Australia 


\title{
Advertisement placed here.
}

\author{
SCS bohn \\ stafleu \\ CL van loghum \\ Springer Media
}

Houten 2018 


\title{
Advertisement placed here.
}

\author{
SCS bohn \\ stafleu \\ CL van loghum \\ Springer Media
}

Houten 2018 